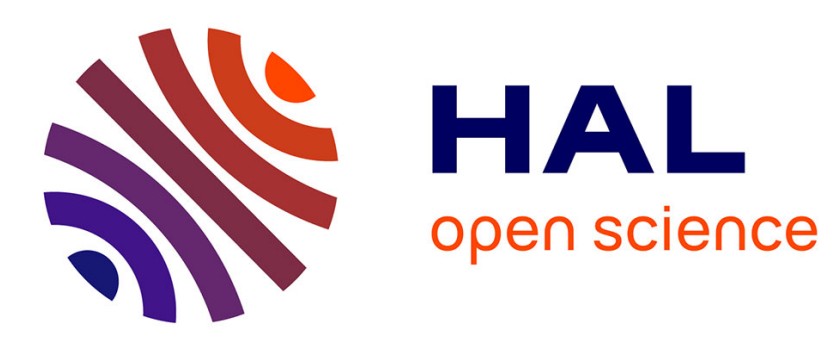

\title{
Spallation Process of Thermally Grown Oxides by In-Situ CCD Monitoring Technique
}

\author{
Qi Yu-Hong, Philippe Lours, Yannick Le Maoult
}

\section{To cite this version:}

Qi Yu-Hong, Philippe Lours, Yannick Le Maoult. Spallation Process of Thermally Grown Oxides by In-Situ CCD Monitoring Technique. Journal of Iron and Steel Research International, 2009, 16 (6), pp.90-94. 10.1016/S1006-706X(10)60034-9 . hal-01709497

\section{HAL Id: hal-01709497 \\ https://hal.science/hal-01709497}

Submitted on 4 Dec 2019

HAL is a multi-disciplinary open access archive for the deposit and dissemination of scientific research documents, whether they are published or not. The documents may come from teaching and research institutions in France or abroad, or from public or private research centers.
L'archive ouverte pluridisciplinaire HAL, est destinée au dépôt et à la diffusion de documents scientifiques de niveau recherche, publiés ou non, émanant des établissements d'enseignement et de recherche français ou étrangers, des laboratoires publics ou privés. 


\title{
Spallation Process of Thermally Grown Oxides by In-Situ CCD Monitoring Technique
}

\author{
QI Yu-hong', Philippe Lours², Yannick Le Maoult ${ }^{2}$ \\ (1. Materials Science and Engineering Department, Dalian Maritime University, Dalian 116026, Liaoning, China; \\ 2. Research (entre on Tools, Materials and Processes, Ecole des Mines, 81013 Albi, France)
}

\begin{abstract}
In cooling process of Fe-Cr-Al alloy oxidized at $1300^{\circ} \mathrm{C}$, the effect of cooling speed and exposure time on oxide spalled area fraction and successive variety of the spalled region were studied by investigating evolvement of the thermally grown oxide using in-situ CCD monitoring technique. The results showed that oxide spallation can be restrained by controlling cooling speed and the critical temperature drop of spallation initiation which is closely related to the oxide thickness or exposure time, and the spallation process of a little region may be described in more detail as two routes: from the oxide/substrate interface micro-decohesion, micro-buckles, buckle spreading, buckle crack to spallation and from the interface micro-decohesion, micro-buckles, buckle crack and spallation to the residual oxide decohesion and spallation.
\end{abstract}

Key words: in-situ CCD monitoring technique; spallation; thermally grown oxide; $\mathrm{Fe}-\mathrm{Cr}-\mathrm{Al}$

High temperature alloys are protected from rapidly oxidizing degradation by the formation of slow growing oxide scales. However, brittle oxides, the weak interfacial adhesion and the thermal stresses in oxide can result in cracking and detachment or spallation. The failure destroys the protective function of oxides. Therefore, evaluation and prediction of the scale crack and spallation is of great importance to understand the failure mechanism of oxide scale and to select correctly material and develop new materials under the service environment ${ }^{[-4]}$. Some methods and techniques of evaluating adhesion of the oxide scales to substrate have been studied. These methods ${ }^{[5-9]}$ are classified into mechanical testing techniques which include direct pulling, double beam bending, scratch tests, indentation technique and spallation monitoring techniques which include thermogravimetric analysis, acoustic emission, $\mathrm{Ra}^{-}$ man spectroscopy and CCD monitoring. Pulling, scratch and microindentation tests are convenient and easy to perform, but only useful for relative comparisons within a given system of some limited alloys. Double beam bending techniques can provide accurate information on the strength or fracture resistance of the interface. However, an adhesive usually has to apply between the fixture and oxide surface. This not only complicates the analysis, but also limits the strength of the interface that can be measured. Thermogravimetric analysis method is to measure the temperature and gross oxide weight gain at initiation of oxide spallation during cooling. Acoustic emission technique has been used as an in-situ monitoring of crack initiation and development of oxide scales on metal. CCD monitoring is a new in-situ technique that focuses on the successive variational morphology and temperature of whole surface during specimen cooling. Spallation monitoring techniques can be used to study the spallation behavior of oxide film and interfacial fracture energy of oxide/metal by monitoring the spallation process of oxide scales and temperature drop during cooling.

The purpose of present work is to study the effect factors and mechanism of oxide spallation by investigating spallation behavior of the whole surface in specimen cooling process using in-situ CCD monitoring technique.

Foundation Item: Item Sponsored by the Scientific Research Foundation for the Returned Overseas Chinese Scholars

Biography: QI Yu-hong(1963-), Female. Doctor, Professor; E-mail: yuhong_qi@dlmu. edu. cn; 


\section{Experimental}

The chemical composition of $\mathrm{Fe}-\mathrm{Cr}-\mathrm{Al}$ high temperature alloy investigated in this paper (mass percent) is given in Table 1. The oxidation experiment was performed in a muffle furnace at $1300{ }^{\circ} \mathrm{C}$ for $194 \mathrm{~h}, 267 \mathrm{~h}, 362 \mathrm{~h}$ and $819 \mathrm{~h}$. Specimens with $8 \mathrm{~mm}$ thick and $30 \times 30 \mathrm{~mm}^{2}$ square were polished and ultrasonically cleaned in acetone prior to oxidation. The scheme of in-situ CCD monitoring the spallation of oxide scales during cooling is shown in Fig. 1. After oxidation, the specimen is removed out and put on the firebrick on which two thermocouple wire ends are fixed to keep good contact with the back of specimen. Monitor, digital recorder and temperature measurement recorder are turned on simultaneously. CCD camera recorded the surface morphology at a second of 30 frames and infra-red thermograph recorded temperature distribution of the specimen surface. Image analysis is used to evaluate the spalled area of the oxide scales. Hardness was tested by Buehler MICROMET 2001 Vickers microhardness tester and morphology and thickness of oxide were examined by scanning electron microscope.

\begin{tabular}{ccccc}
\multicolumn{2}{c}{ Table 1} & \multicolumn{4}{c}{ Composition of } & Fe-Cr-Al alloy & $\%$ \\
\hline$w(\mathrm{Fe})$ & $w(\mathrm{Cr})$ & $w(\mathrm{Al})$ & $w(\mathrm{Ti})$ & $w\left(\mathrm{Y}_{2} \mathrm{O}_{3}\right)$ \\
\hline Balance & 20 & 5.5 & 0.5 & 0.5 \\
\hline
\end{tabular}

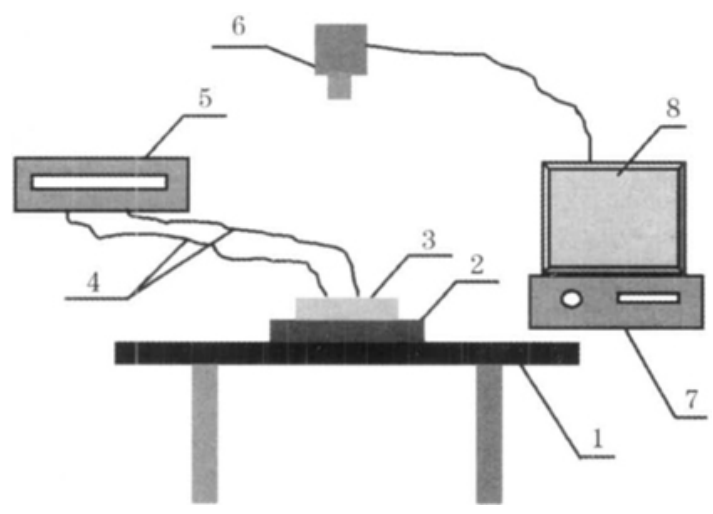

1-Worktable; 2-Firebrick; 3-Specimen; 4-Thermocouples; 5-Temperature recorder; 6-CCD camera or IR thermograph; 7-Digital recorder; 8-Monitor

Fig. 1 Scheme of in-situ CCD monitoring device

\section{Results and Discussion}

\section{1 Oxidation kinetics}

The samples are oxidized at $1300{ }^{\circ} \mathrm{C}$ for $194 \mathrm{~h}$,
$267 \mathrm{~h}, 362 \mathrm{~h}$ and $819 \mathrm{~h}$ and the oxide thickness are $14.91,17.86,19.71$ and $31.13 \mu \mathrm{m}$, respectively. The oxidation kinetics curve is shown in Fig. 2, from which oxide thickness $\xi$ increases with oxide exposure time $t$. Eqn. (1) can be obtained by curve fitting which accords with a parabola relationship. $\xi=1.034 t^{0.506}$

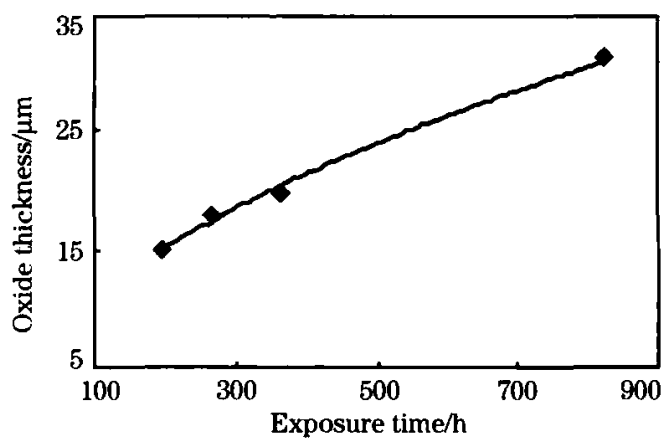

Fig. 2 Oxidation kinetics curves

\subsection{Effect of cooling speed}

During the sample cooling, the oxide film is possible to crack and spall under the driving force of compressive stresses that are produced from oxide growth and shrinking difference between oxide film and substrate due to their different thermal expansion coefficients. The initial temperature drop and surface area fraction of oxide spallation are mainly relative to the oxidation temperature, the cooling speed and the exposure time as well as the intrinsic mechanical properties of the substrate, the oxide and their bonding interface. The surface of specimens oxidized at $1300{ }^{\circ} \mathrm{C}$ for $267 \mathrm{~h}$ is observed at ambient temperature after cooling in furnace, on firebrick in air (Fig. 1) and on ice fragments in air respectively. When cooling in furnace, no spallation occurred, but there are some cracks on oxide surface [Fig. 3 (a)]. Serious spallation occurred for the specimen cooled on firebrick in air [Fig. 3(b)], whereas near fully spallation when cooling on ice fragments in air [Fig. 3 (c)]. Therefore, cooling speed has an obvious effect on oxide spallation. During cooling, the spallation of oxide film is mainly due to the compressive stress in oxide caused from mismatch of thermal expansion coefficients between substrate and oxide. The more rapid the cooling speed is, the greater the stress is.

Fig. 4 shows the scale spalled morphology of the specimen cooled on firebrick in air. When the surface temperature falls to about $307{ }^{\circ} \mathrm{C}$ [Fig. 4 (a)], 


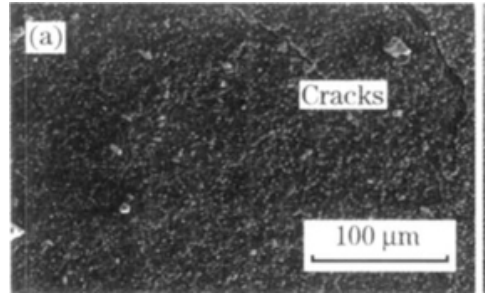

(a) In furnace;
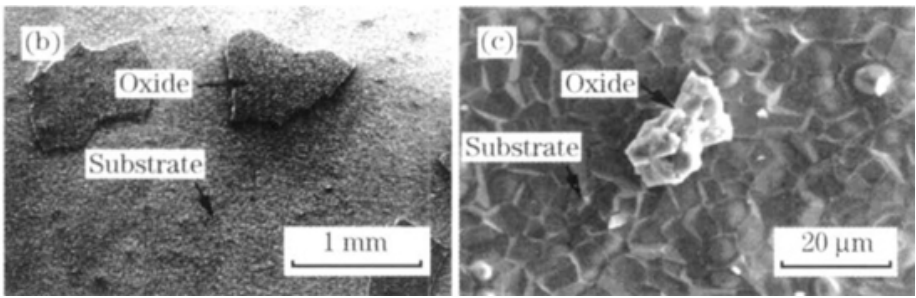

(b) On firebrick in air;

(c) ()n ice fragments in air

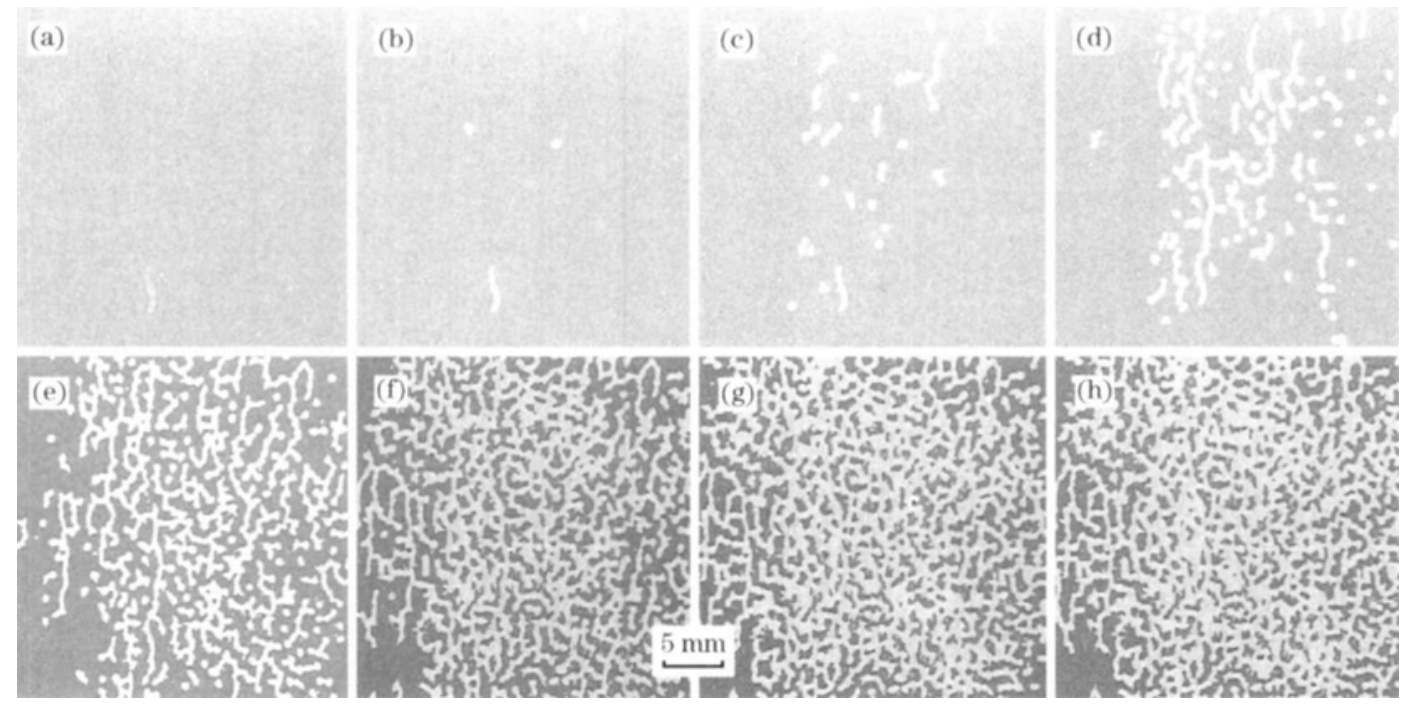
(a) $282.17 \mathrm{~s}, 307 \mathrm{C}, 0.22 \%$;
(b) $299.80 \mathrm{~s}, 255 \mathrm{C}, 3.06 \%$;
(c) $359.80 \mathrm{~s}, 255 \mathrm{C}, 3.06 \%$,
(d) $419.80 \mathrm{~s}, 223 \mathrm{C}, 11.96 \%$
(e) $539.80 \mathrm{~s} .176 \mathrm{C}, 28.62 \%$;
(f) $719.80 \mathrm{~s}, 130 \mathrm{C} \cdot 47.04 \%$;
(g) $959.80 \mathrm{~s}, 93 \mathrm{C}, 56.25 \%$;
(h) $1193.80 \mathrm{~s}, 72 \mathrm{C} .62 .24 \%$

Fig. 4 Scale spalled morphology of specimen oxidized at $1300^{\circ} \mathrm{C}$ for $267 \mathrm{~h}$ during cooling

the oxide film begins to spall in the vermiculate morphology. The oxide spalled area increases subsequently with the specimen temperature falling. The spalled sites are random, but the spalled initial temperature is higher and the spalled area fraction is more in specimen centre than in specimen edges. The morphology of most spalled region is vermiculate and round.

Surface temperature distribution of cooling to $100 \mathrm{~s}$ for the specimen oxidized at $1300{ }^{\circ} \mathrm{C}$ for $267 \mathrm{~h}$ are recorded by infra-red thermograph (Fig. 5). The cooling curves of spot $1,2,3$ and 4 in Fig. 5 are drawn in Fig. 6 respectively. According to Fig. 5 and Fig. 6, there is no spallation in spot 3 in which the cooling curve is smooth, and the scales on spot 1,2 and 4 have been spalled off in which the cooling curves are discontinuous. The sharp drop points show the onset of scale spallation from which the temperature and time of scale spallation initiation at spot 1,2 and 4 are $520^{\circ} \mathrm{C}$, $15 \mathrm{~s}, 515{ }^{\circ} \mathrm{C}, 20 \mathrm{~s}$ and $396{ }^{\circ} \mathrm{C}, 94 \mathrm{~s}$, respectively.
Therefore, formation time, shape, size and position of oxide spallation region are random for the same specimen, which depend on the distribution of compressive stresses in oxide film.

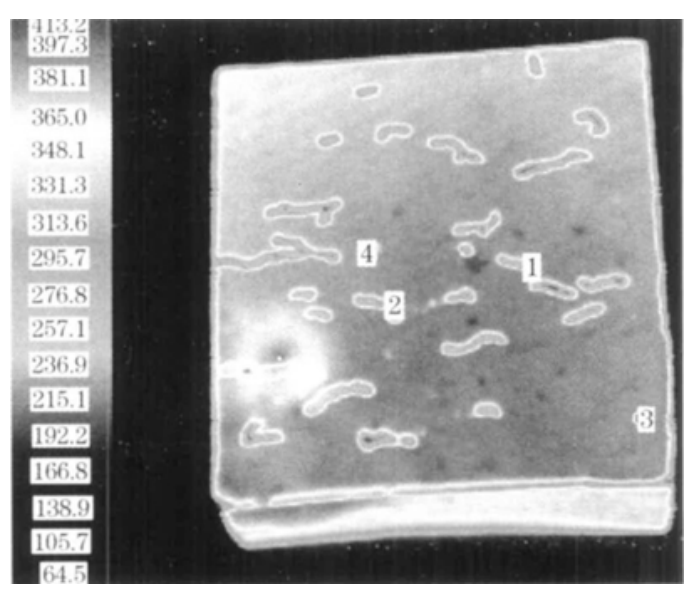

Fig. 5 Surface temperature distribution of oxide 


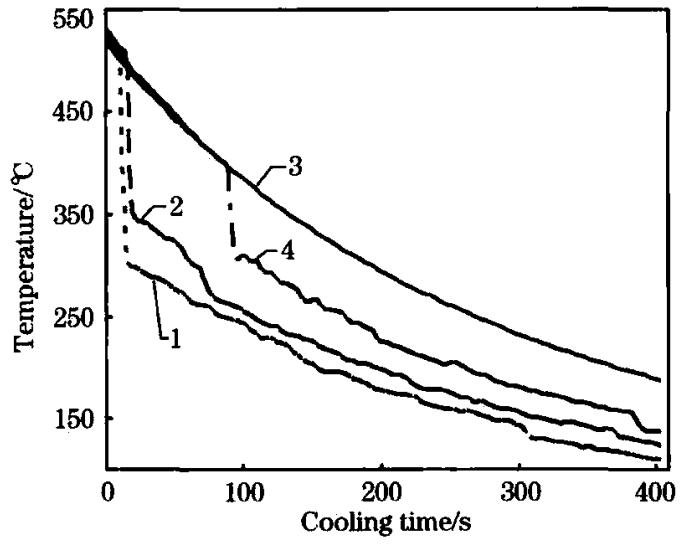

Fig. 6 Cooling curves of spot 1, 2, 3 and 4 in Fig. 5

\subsection{Effect of exposure time}

The area of scale spallation increases with temperature falling for four samples oxidized at $1300{ }^{\circ} \mathrm{C}$ for $194 \mathrm{~h}, 267 \mathrm{~h}, 362 \mathrm{~h}$ and $819 \mathrm{~h}$. The variation curves of the area spalled with specimen temperature are shown in Fig. 7. During cooling when oxide film is cooled to some temperature, that is, the temperature of spallation initiation, the scale spallation began and the area spalled increase rapidly with specimen cooling. The spallation ended at about $60-80{ }^{\circ} \mathrm{C}$. The area, initial temperature and end temperature of scale spallation are mainly related to the oxide thickness, and increase with oxide thickness increasing. The critical temperature drop $\Delta T_{\mathrm{c}}$ of spallation initiation, that is the difference between oxide temperature and initial spallation temperature, is an important parameter to characterize the adhesion of oxide film which is closely related to the scale thickness $\xi$ or oxide exposure time. The $\Delta T_{\mathrm{c}}$ value is correspondingly $1069,1035,1005$ and 768 for the specimens with oxide thickness of $14.91 \mu \mathrm{m}, 17.86 \mu \mathrm{m}$,

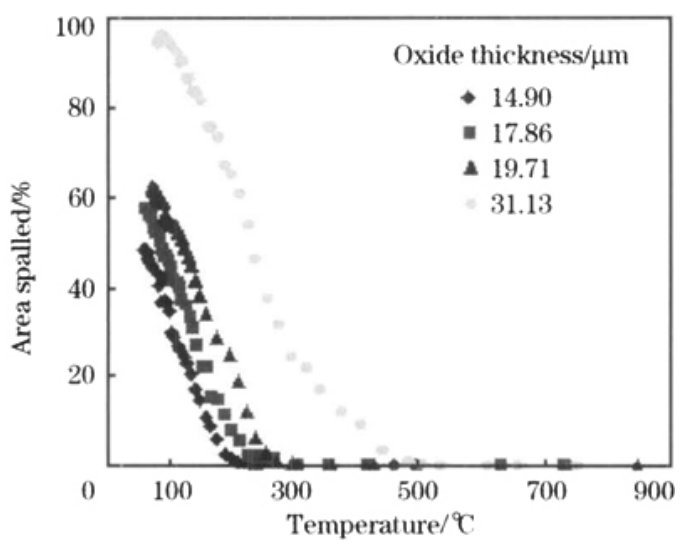

Fig. 7 Variation of area spalled with specimen temperature
19. $71 \mu \mathrm{m}$ and $31.13 \mu \mathrm{m}$. The curve fitting equation of $\Delta T_{\mathrm{c}}$ with $\xi$ is expressed as follows:

$$
\Delta T_{\mathrm{c}}=1127+3.21 \xi-0.47 \xi^{2}
$$

An alternative form of Eqn. (2) is obtained by substituting Eqn. (1) for $\xi$,

$$
\Delta T_{\mathrm{c}}=1127+3.32 t^{0.506}-0.49 t^{1.12}
$$

Eqn. (3) can be used to predict initial spallation temperature of $\mathrm{Fe}-\mathrm{Cr}-\mathrm{Al}$ alloy after any exposure time at high temperature $1300{ }^{\circ} \mathrm{C}$.

\section{4 Microstructure of spalled region and spallation mechanism}

When the specimen oxidized at $1300{ }^{\circ} \mathrm{C}$ for $362 \mathrm{~h}$ is cooled to $211 \mathrm{~s}$, the successive evolvement of a spalled region is shown in Fig. 8. No spallation occurred in the 13 th frame $[$ Fig. 8 (a)] at $211 \mathrm{~s}$, whereas in the 15 th frame $[\mathrm{Fig.} 8$ (b)], there is a spalled region which consists of many parallel strips of non spalled oxide film, but in the 17 th frame [Fig. 8 (c)], the parallel oxide strips peel fully off. The similar phenomena also occurred in other three specimens. The articles on such oxide spalling process have not read yet.

Evans et $\mathrm{al}^{[6,7]}$ considered that there are two typical processes of spallation for thermally grown oxide film under compressive stresses. If oxide/metal interface has a high adhesive strength relative to the cohesive strength of the oxide, cracking of the oxide will take place before decohesion, whereas poor interface adhesion will result in decohesion before oxide cracking. In this work, more detailed spallation process has been observed (Fig. 8 ) by in-situ CCD monitoring. Therefore, spallation mechanism may be described in more detail as Fig. 9.

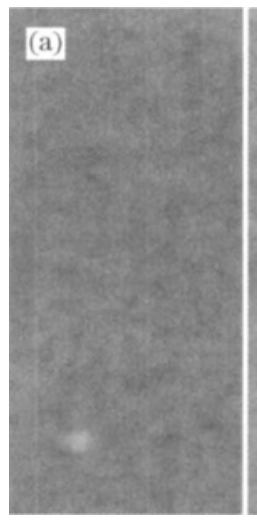

(a) $211.43 \mathrm{~s}$;

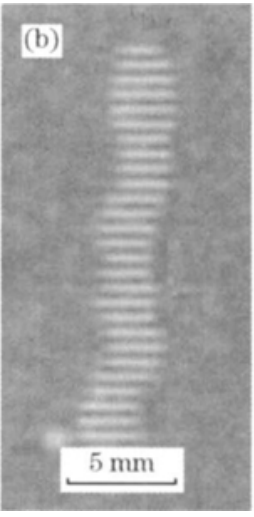

(b) $211.50 \mathrm{~s}$;

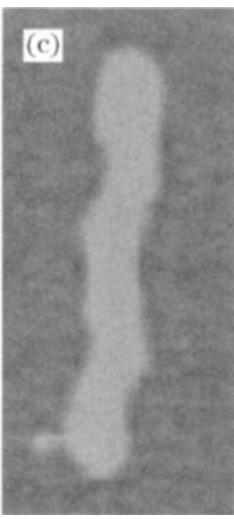

(c) $211.57 \mathrm{~s}$
Fig. 8 Successive evolvement of surface spalled region for specimen oxidized at $1300{ }^{\circ} \mathrm{C}$ for $362 \mathrm{~h}$ during cooling 


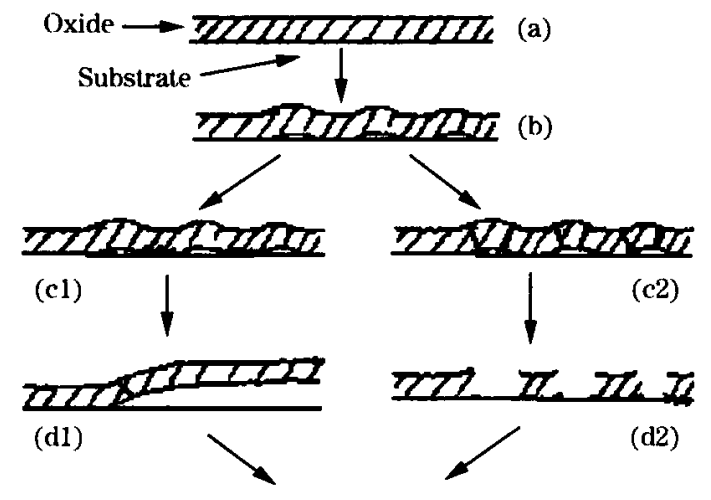

(e) 272

Fig. 9 Sketch of spallation process for $\mathrm{Fe}-\mathrm{Cr}-\mathrm{Al}$ alloy

The thermal stress in oxide leads to many localized micro-decohesion and micro-buckles [Fig. 9 (a) to (b)] in a little region; then if oxide is stronger, the buckles may spread to all region into a large buckle [Fig. $9(\mathrm{cl})$ to $(\mathrm{d} 1)]$ under compressive stress and the buckled scale produce cracks under tensile stress and lead to spallation [Fig. 9 (dl) to (e)], whereas the weak oxide buckles will result in crack and spalation [Fig. 9 (c2) to (d2)] under tensile stress, subsequently decohesion and spalation [Fig. 9 (d2) to (e)] take place for the other oxides between the buckles under compressive stress. This work provides a good support for Evans' buckling spallation rouțe ${ }^{[7]}$.

\section{Conclusions}

(1) During oxide spallation process caused by air cooling, temperature, time, shape and size of any spalled region can be obtained by in-situ CCD monitoring method.

(2) The oxide spalled area increases with decreasing the specimen temperature. The spalled sites are random, but the spalled initial temperature is higher and the spalled area fraction is more in speci- men centre than in specimen edges.

(3) The critical temperature drop $\Delta T_{\mathrm{c}}$ of spallation initiation is closely related to the scale thickness $\xi$ or oxide exposure time $t$ that may be expressed as follows:

$$
\begin{aligned}
& \Delta T_{\mathrm{c}}=1127+3.21 \xi-0.47 \xi^{2} \\
& \Delta T_{\mathrm{c}}=1127+3.32 t^{0.506}-0.49 t^{1.12}
\end{aligned}
$$

The equations can be used to predict and control the spallation of thermally grown oxides.

(4) The spallation process of a little region may be described as micro-decohesion $\rightarrow$ micro-buckles $\rightarrow$ buckle spreading $\rightarrow$ buckle crack $\rightarrow$ spallation or microdecohesion $\rightarrow$ micro-buckles $\rightarrow$ buckle crack and spallation $\rightarrow$ the residual oxide decohesion and spallation.

\section{References:}

[1] Evans H E. Stress Effects in High Temperature Oxidation of Metals [J]. International Materials Reviews, 1995 , 40(1) : 1.

[2] McCartney L. N. Modelling Scale Failure in Tension (Fracture and Spallation) [J]. Materials at High Temperatures, 2005, 22(1-2): 167 .

[3] Bamba G. Wouters Y, Galerie A, et al. Thermal Oxidation Kinetics and ()xide Scale Adhesion of Fe-15Cr Alloys as a Function of Their Silicon Content [J]. Acta Materialia, 2006. 54(15): 3917.

[4] Evans H E. Spallation Models and Their Relevance to SteamGrown ()xides [J]. Materials at High Temperatures, 2005, 22 (1-2): 155.

[5] Hou P Y, Saunders S R J. A Survey of Test Methods for Scale Adhesion Measurement [J]. Materials at High Temperatures, 2005. 22(1-2): 121 .

[6] Evans H E. Spallation of Oxide From Stainless Steel Agr Nuclear Fuel Cladding: Mechanisms and Consequences [J]. Mater Sci Technol, 1987, 4: 415.

[7] Nishiyama Y. Kitamura K. Kudo T, et al. In Situ Evaluations for Spallation of $\mathrm{Cr}_{2} \mathrm{O}_{3}$ Scale by $\mathrm{AE}$ and Raman Spectroscopy [J]. Journal of the Japan Institute of Metals, 2007, 71(1): 55 (in Japanese).

[8] Lours P. Maoult Y, Ade D, et al. Direct Examinations of ( $X_{-}-$ ide Scales Upon Cooling: A New Way to Analyse ()xide Scale Spallation [J]. Materials Science Forum. 2004. 461-464 (II) : 639.

[9] Lours P, Qi Y, I,e Maoult Y, et al. In Situ and ex Situ Investigation of the Spallation of Thermally Grown Oxides [J]. Materials Science Forum. 2007. 539-543(2): 1134. 